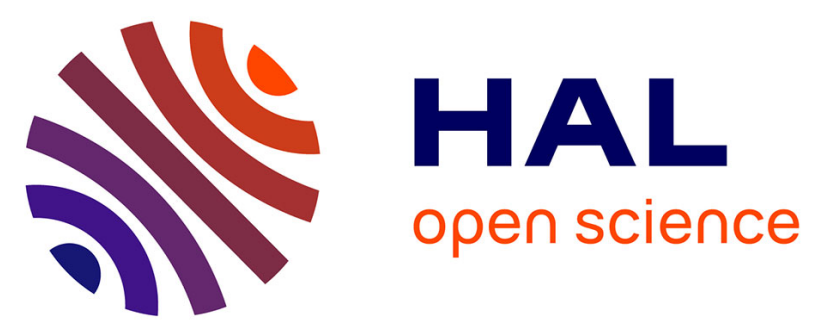

\title{
Inhibition of the Receptor for Advanced Glycation End-Products in Acute Respiratory Distress Syndrome: A Randomised Laboratory Trial in Piglets.
}

Jules Audard, Thomas Godet, Raiko Blondonnet, Jean-Baptiste Joffredo, Bertille Paquette, Corinne Belville, Marilyne Lavergne, Christelle Gross, Justine Pasteur, Damien Bouvier, et al.

\section{To cite this version:}

Jules Audard, Thomas Godet, Raiko Blondonnet, Jean-Baptiste Joffredo, Bertille Paquette, et al.. Inhibition of the Receptor for Advanced Glycation End-Products in Acute Respiratory Distress Syndrome: A Randomised Laboratory Trial in Piglets.. Scientific Reports, 2019, 9 (1), pp.9227. 10.1038/s41598-019-45798-5 . hal-03023315

\section{HAL Id: hal-03023315 \\ https://hal.uca.fr/hal-03023315}

Submitted on 4 Jun 2021

HAL is a multi-disciplinary open access archive for the deposit and dissemination of scientific research documents, whether they are published or not. The documents may come from teaching and research institutions in France or abroad, or from public or private research centers.
L'archive ouverte pluridisciplinaire HAL, est destinée au dépôt et à la diffusion de documents scientifiques de niveau recherche, publiés ou non, émanant des établissements d'enseignement et de recherche français ou étrangers, des laboratoires publics ou privés. 
Received: 5 September 2018

Accepted: 12 June 2019

Published online: 25 June 2019
ENTIFIC REPRTS

Inhibition of the Receptor for Advanced Glycation End-Products in Acute Respiratory Distress Syndrome: A Randomised Laboratory Trial in Piglets

\author{
Jules Audard ${ }^{1,2}$, Thomas Godet ${ }^{1,2}$, Raiko Blondonnet $\mathbb{D}^{1,2}$, Jean-Baptiste Joffredo ${ }^{1,2}$, \\ Bertille Paquette $^{1,2}$, Corinne Belville ${ }^{2}$, Marilyne Lavergne ${ }^{2}$, Christelle Gross ${ }^{2}$, \\ Justine Pasteur ${ }^{3}$, Damien Bouvier ${ }^{2,4}$, Loic Blanchon ${ }^{2}$, Vincent Sapin ${ }^{2,4}$, Bruno Pereira ${ }^{5}$, Jean- \\ Michel Constantin ${ }^{1,2}$ \& Matthieu Jabaudon $\mathbb{D D}^{1,2}$
}

The receptor for advanced glycation end-products (RAGE) modulates the pathogenesis of acute respiratory distress syndrome (ARDS). RAGE inhibition attenuated lung injury and restored alveolar fluid clearance (AFC) in a mouse model of ARDS. However, clinical translation will require assessment of this strategy in larger animals. Forty-eight anaesthetised Landrace piglets were randomised into a control group and three treatment groups. Animals allocated to treatment groups underwent orotracheal instillation of hydrochloric acid (i) alone; (ii) in combination with intravenous administration of a RAGE antagonist peptide (RAP), or (iii) recombinant soluble (s)RAGE. The primary outcome was net AFC at $4 \mathrm{~h}$. Arterial oxygenation was assessed hourly and alveolar-capillary permeability, alveolar inflammation and lung histology were assessed at $4 \mathrm{~h}$. Treatment with either RAP or sRAGE improved net AFC (median [interquartile range], 21.2 [18.8-21.7] and 19.5 [17.1-21.5] \%/h, respectively, versus 12.6 [3.2-18.8] \%/h in injured, untreated controls), oxygenation and decreased alveolar inflammation and histological evidence of tissue injury after ARDS. These findings suggest that RAGE inhibition restored AFC and attenuated lung injury in a piglet model of acid-induced ARDS.

Acute respiratory distress syndrome (ARDS) is a frequent cause of respiratory failure and death in critically ill patients ${ }^{1}$. ARDS currently lacks effective therapies, although lung-protective ventilation and reasoned fluid management remain essential for better outcomes ${ }^{2,3}$. ARDS is a clinical syndrome ${ }^{4}$ characterised by diffuse alveolar epithelial and lung endothelial injury that leads to increased permeability pulmonary oedema, alveolar filling and respiratory failure ${ }^{2}$. The resolution of alveolar oedema and ARDS requires that the alveolar epithelial fluid transport function remain intact, which suggests that a strategy aimed at improving alveolar fluid clearance (AFC) may be beneficial for recovery from ARDS ${ }^{5,6}$. The main mechanism responsible for the reabsorption of the water fraction of the oedema fluid from the airspaces of the lungs is active ion transport across the alveolar epithelium, which occurs primarily through the operation of the epithelial sodium channel (ENaC), Na, K-ATPase and aquaporin (AQP) $-5^{7}$.

The lung alveolar type (AT)-1 cells abundantly express the receptor for advanced glycation end-products (RAGE) as a transmembrane pattern-recognition receptor ${ }^{8,9}$ and RAGE may play a central role in the pathogenesis of ARDS ${ }^{8,10-13}$. The activation of RAGE modulates cell signalling that leads to a sustained inflammatory response through various intracellular signalling pathways that typically lead to pro-inflammatory activation of

${ }^{1}$ Department of Perioperative Medicine, CHU Clermont-Ferrand, Clermont, Ferrand, France. ${ }^{2}$ Université Clermont Auvergne, CNRS UMR 6293, INSERM U1103, GReD, Clermont, Ferrand, France. ${ }^{3}$ Department of Dermatology, CHU Clermont-Ferrand, Clermont, Ferrand, France. ${ }^{4}$ Department of Medical Biochemistry and Molecular Biology, CHU Clermont-Ferrand, Clermont, Ferrand, France. ${ }^{5}$ Biostatistical and Data Management Unit, Department of Clinical Research and Innovation (DRCl), CHU Clermont-Ferrand, Clermont, Ferrand, France. Correspondence and requests for materials should be addressed to M.J. (email: mjabaudon@chu-clermontferrand.fr) 


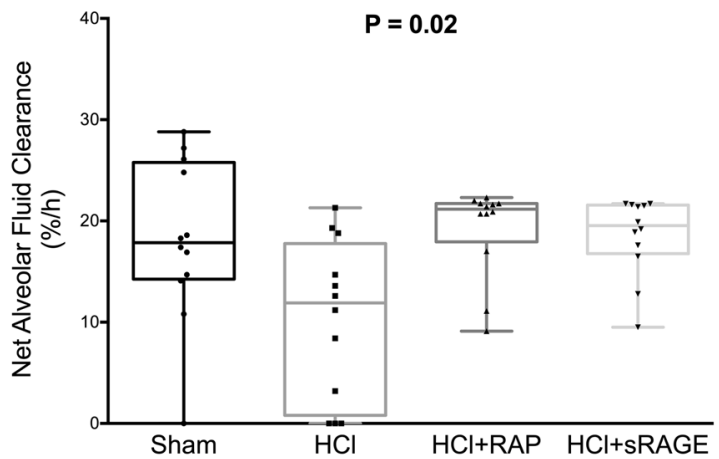

Figure 1. RAGE inhibition restores alveolar fluid clearance after acid-induced lung injury. Measurement of net alveolar fluid clearance (AFC) rate as a marker of epithelial function in uninjured (Sham), acid-injured $(\mathrm{HCl})$ and acid-injured piglets treated with RAGE antagonist peptide $(\mathrm{HCl}+\mathrm{RAP})$ or recombinant sRAGE $(\mathrm{HCl}+\mathrm{sRAGE})(\mathrm{n}=12$ per group at each time point). Values are reported as box and whisker plots. The Kruskal-Wallis test, with post-hoc Bonferroni test for pairwise comparisons were used. $\mathrm{P}=0.02$ for the overall multiple group test; no statistical difference was found in post-hoc tests.

nuclear transcription factor NF- $\kappa$ B and upregulation of RAGE itself ${ }^{9}$. Plasma levels of soluble RAGE (sRAGE) show a positive association with the extent and severity of lung injury, the degree of AFC impairment and worse clinical outcomes in ARDS ${ }^{10-12,14-16}$.

Recent findings in genetically deficient $\left(\mathrm{RAGE}^{-1-}\right)$ mice or rats treated with an anti-RAGE antibody suggest that targeting RAGE might be a beneficial therapy for treatment of experimental sepsis and pneumonia ${ }^{17,18}$. In addition, the administration of sRAGE, which acts as a decoy receptor to prevent interactions between transmembrane RAGE and its ligands, decreased the alveolar inflammation and lung permeability in mice with lipopolysaccharide (LPS)-induced lung injury ${ }^{19}$. Our team recently showed that treatment with either an anti-RAGE monoclonal antibody or sRAGE attenuated lung injury, improved arterial oxygenation and decreased alveolar inflammation in a translational model of acid-injured mice ${ }^{20}$. The anti-RAGE therapies restored AFC and increased lung expression of AQP-5 in alveolar cells, thereby providing a possible link between RAGE modulation and the mechanisms of lung epithelial injury and repair relevant to clinical ARDS ${ }^{7}$.

However, this type of strategy for RAGE inhibition has never been tested in a large animal model, either to determine the precise functional and biological effects of RAGE modulation in ARDS or in preparation for translation of this strategy to the clinical setting as an ARDS treatment. The aim of the present randomised trial was to investigate the potential therapeutic roles of either recombinant sRAGE or a RAGE antagonist peptide (RAP) on AFC and to establish the main features of experimental ARDS in a piglet model of hydrochloric acid (HCl)-induced ARDS. RAP is a small S100P-derived peptide with similar blocking effects to those of anti-RAGE monoclonal antibody, as it prevents RAGE from binding with several of its most important ligands, including HMGB1 and S100 proteins, in cancer cells in vitro and in vivo ${ }^{21}$.

Some of the results of this study have been previously reported in the form of an abstract during the American Thoracic Society International Conference (2017).

\section{Results}

Alveolar fluid clearance. A significant between-group difference was detected in net AFC rates measured after four hours of mechanical ventilation $(\mathrm{P}=0.02)$ (Fig. 1). The net AFC rate was decreased in $\mathrm{HCl}$-injured piglets $(12.6[3.2-18.8] \% / \mathrm{h})$ when compared with sham animals $(17.9[14.4-25.5] \% / \mathrm{h})$. By contrast, treatment with RAP (21.2 [18.8-21.7] \%/h) or sRAGE (19.5 [17.1-21.5] \%/h) restored AFC in the HCl-injured animals.

Arterial oxygenation. Two-way repeated measures analyses of variance (ANOVA) indicated a group effect $(\mathrm{P}=0.001)$, a time effect $(\mathrm{P}=0.03)$ and a significant interaction $\left(\mathrm{P}<10^{-4}\right)$ with a detrimental effect of $\mathrm{HCl}$-induced ARDS on the course of arterial oxygen tension $\left(\mathrm{PaO}_{2}\right)$ /inspiratory oxygen fraction $\left(\mathrm{FiO}_{2}\right)$, when compared with the absence of ARDS or with the use of an anti-RAGE therapy with either RAP or sRAGE in animals with ARDS (Fig. 2). $\mathrm{PaO}_{2} / \mathrm{FiO}_{2}$ decreased by $25 \%$ at one hour (301 [223-405] mmHg) in untreated ARDS animals, and this decrease remained stable throughout the experiment in those animals $(314$ [186-447] $\mathrm{mmHg}$ at four hours). In both groups of ARDS animals treated with RAP or sRAGE, arterial oxygenation was preserved at all time points when compared with otherwise untreated, injured animals (419 [385-452] and 431 [412-466] $\mathrm{mmHg}$ at four hours, respectively). $\mathrm{PaO}_{2} / \mathrm{FiO}_{2}$ was higher in sham than in untreated, injured animals at one hour, two, three and four hours $\left(\mathrm{P}<10^{-2}, \mathrm{P}<10^{-2}, \mathrm{P}<10^{-2}\right.$ and $\mathrm{P}<10^{-2}$, respectively).

Alteration of the Alveolar-Capillary barrier. A significant between-group difference was noted in lung bronchoalveolar lavage (BAL) levels of total protein measured after four hours of mechanical ventilation $\left(\mathrm{P}=10^{-4}\right)$ (Fig. 3A). HCl-induced ARDS was associated with increased BAL protein (6.1 [3.1-7.7] g.L $\left.{ }^{-1}\right)$, when compared with sham animals $\left(0.3[0.2-0.7] \mathrm{g} . \mathrm{L}^{-1}\right)$ and animals treated with either RAP $\left(1.2[0.9-2.1] \mathrm{g} . \mathrm{L}^{-1}\right)$ or sRAGE (1.3 [1.0-2.1] g.L $\left.\mathrm{L}^{-1}\right)$.

Two-way repeated-measurement ANOVA indicated a group effect $(\mathrm{P}=0.03)$, a time effect $\left(\mathrm{P}<10^{-4}\right)$, and a significant interaction $(\mathrm{P}=0.01)$ with an incremental effect of $\mathrm{HCl}$-induced injury on the course of extravascular 


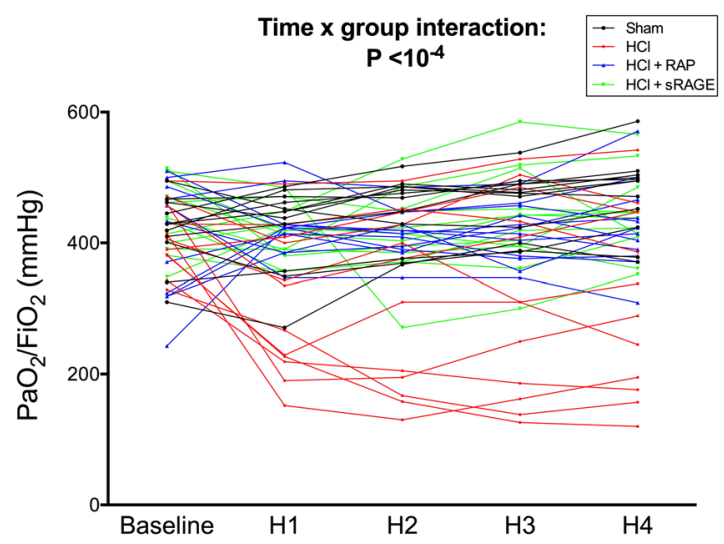

Figure 2. RAGE inhibition improves arterial oxygenation after acid-induced lung injury. Arterial oxygen tension $\left(\mathrm{PaO}_{2}\right)$ /inspiratory oxygen fraction $\left(\mathrm{FiO}_{2}\right)$ in uninjured (Sham), acid-injured $(\mathrm{HCl})$ and acid-injured piglets treated with RAGE antagonist peptide $(\mathrm{HCl}+\mathrm{RAP})$ or recombinant sRAGE $(\mathrm{HCl}+\mathrm{sRAGE})(\mathrm{n}=12$ per group at each time point). Individual values are reported. Time $\times$ group interaction and post-hoc comparisons were verified using random effects models to analyse longitudinal evolution of variables.

A
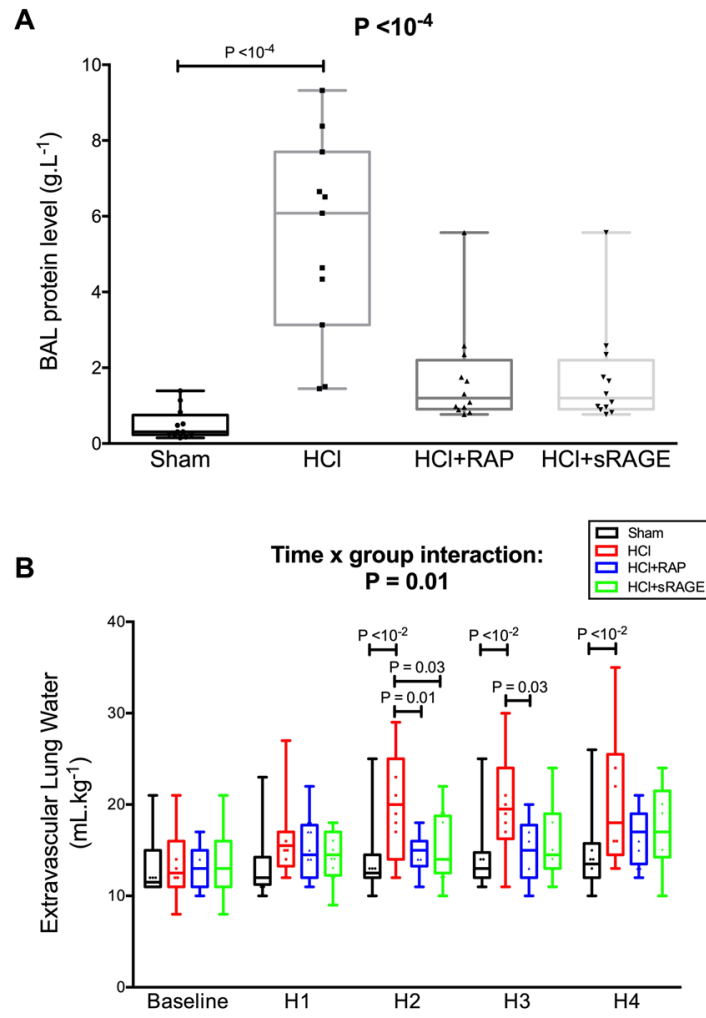

Figure 3. RAGE inhibition decreases alveolar-capillary permeability after acid-induced lung injury. Values are reported as box and whisker plots. (A) Level of total protein in the bronchoalveolar lavage (BAL) fluid from uninjured (Sham), acid-injured $(\mathrm{HCl})$ and acid-injured piglets treated with RAGE antagonist peptide $(\mathrm{HCl}+\mathrm{RAP})$ or recombinant sRAGE $(\mathrm{HCl}+\mathrm{sRAGE})(\mathrm{n}=12$ per group $)$. The Kruskal-Wallis test, with post-hoc Bonferroni test for pairwise comparisons were used. (B) Extravascular lung water, as measured by transpulmonary thermodilution (Picco +, Pulsion SA) and indexed to body weight, in uninjured (Sham), acidinjured $(\mathrm{HCl})$ and acid-injured piglets treated with RAGE antagonist peptide $(\mathrm{HCl}+\mathrm{RAP})$ or recombinant sRAGE $(\mathrm{HCl}+\mathrm{sRAGE})(\mathrm{n}=12$ per group at each time point $)$. Time $\times$ group interaction and post-hoc comparisons were verified using random effects models to analyse longitudinal evolution of variables. 

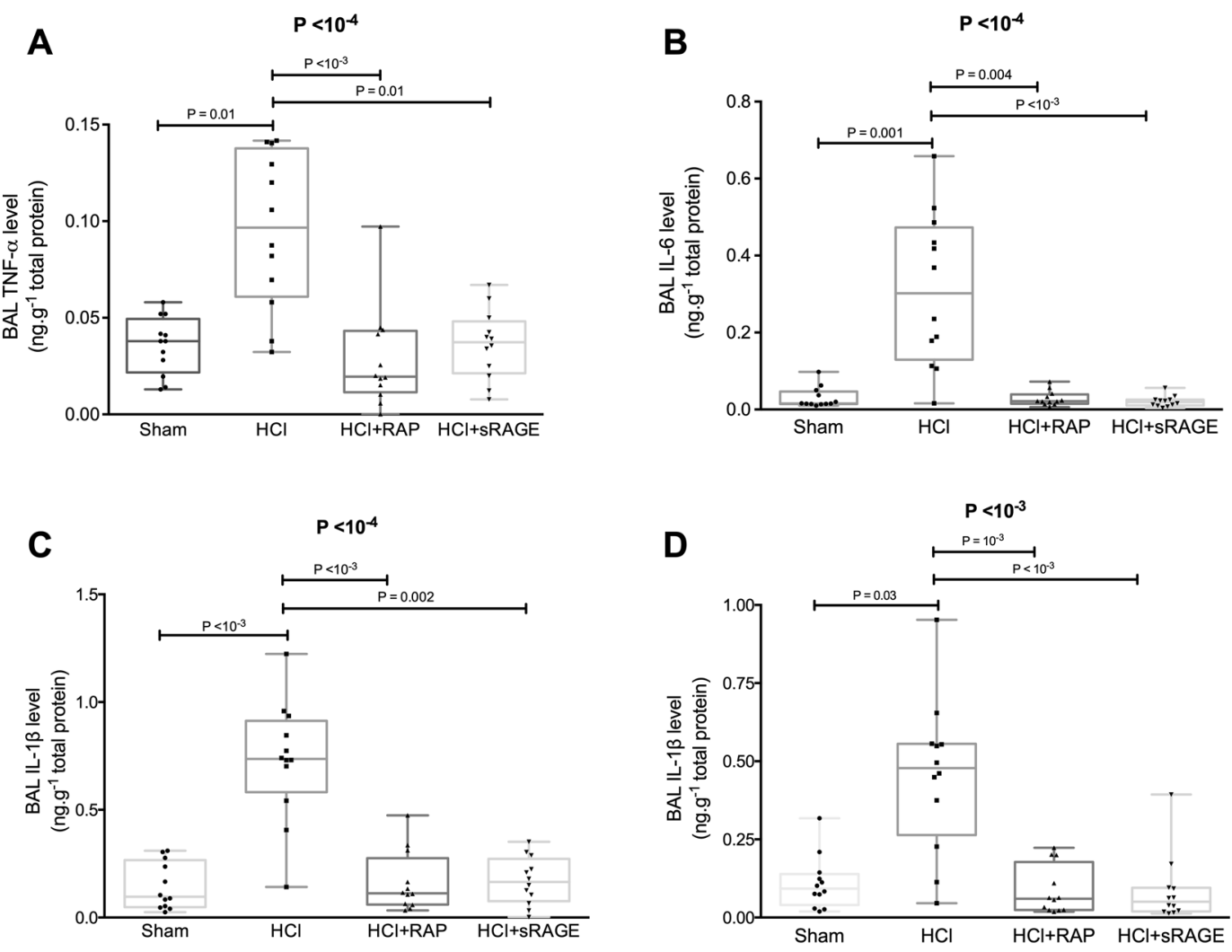

Figure 4. RAGE inhibition decreases alveolar inflammation after acid-induced lung injury. Measurement of bronchoalveolar lavage (BAL) levels of (A) tumour necrosis factor (TNF)- $\alpha$, (B) interleukin (IL)-6, (C) IL-1 $\beta$ and (D) IL-18 in uninjured (Sham), acid-injured ( $\mathrm{HCl})$ and acid-injured piglets treated with RAGE antagonist peptide $(\mathrm{HCl}+\mathrm{RAP})$ or recombinant sRAGE $(\mathrm{HCl}+\mathrm{sRAGE})(\mathrm{n}=12$ per group). Values are reported as box and whisker plots. The Kruskal-Wallis test, with post-hoc Bonferroni test for pairwise comparisons were used.

mL. $\mathrm{kg}^{-1}$ at four hours). However, EVLW was lower in animals treated with RAP or sRAGE than in untreated $\mathrm{HCl}$-injured animals at two hours $(\mathrm{P}=0.01$ and $\mathrm{P}=0.03$, respectively $)$. At three hours, EVLW was lower in animals treated with RAP than in untreated $\mathrm{HCl}$-injured animals $(\mathrm{P}=0.03)$.

Measurement of the inflammatory response. BAL levels of tumour necrosis factor (TNF)- $\alpha(0.09$ $[0.06-0.14]$ ng.g ${ }^{-1}$ total protein), interleukin (IL) -6 (0.13 [0.30-0.47] ng.g ${ }^{-1}$ total protein), IL-1 $\beta$ (0.74 [0.58$0.91] \mathrm{ng} \cdot \mathrm{g}^{-1}$ total protein) and IL-18 (0.48 [0.26-0.56] ng. $\mathrm{g}^{-1}$ total protein) were significantly higher in injured animals than in uninjured controls $(0.04$ [0.02-0.05], 0.02 [0.01-0.05], 0.09 [0.05-0.27] and 0.09 [0.04-0.14] ng. $\mathrm{g}^{-1}$ total protein; $\mathrm{P}=0.01, \mathrm{P}=0.001, \mathrm{P}<10^{-3}$ and $\mathrm{P}=0.03$, respectively). By contrast, BAL levels of cytokines were similar in the sham group and in injured animals treated with RAP or sRAGE (Fig. 4).

Histological evidence of tissue injury. Lung injury scores were higher in untreated HCl-injured animals than in sham controls or in HCl-injured animals treated with RAP or sRAGE (Fig. 5). When compared to sham animals, alveolar wall thickening and neutrophilic alveolar-interstitial infiltrates were more evident in acid-induced than in non-injured piglets. The ARDS animals treated with RAP or sRAGE had less intense neutrophilic infiltration when compared to untreated acid-injured animals.

Other respiratory and hemodynamic variables. The values for tidal volume, $\mathrm{PaCO} 2$, mean arterial pressure, cardiac index and serum lactate did not differ between groups over time (Supplementary Table 2). However, experimental ARDS was associated with a marked decrease in the compliance of the respiratory system at 1-4 hours after injury, when compared to the baseline, the absence of injury or treatment with RAP and sRAGE. Conversely, the inspiratory plateau and driving pressures were increased after acid injury at 1-4 hours after injury, when compared to the baseline, the absence of injury or treatment with RAP and sRAGE.

\section{Discussion}

The main goal of this study was to determine the impact of a RAGE inhibition strategy, based either on sRAGE or RAP administration, in a piglet model of $\mathrm{HCl}$-induced ARDS ${ }^{12,22}$. Here, we demonstrated that both sRAGE and RAP had similar beneficial effects on the symptoms of experimental ARDS, including restoration of AFC, 

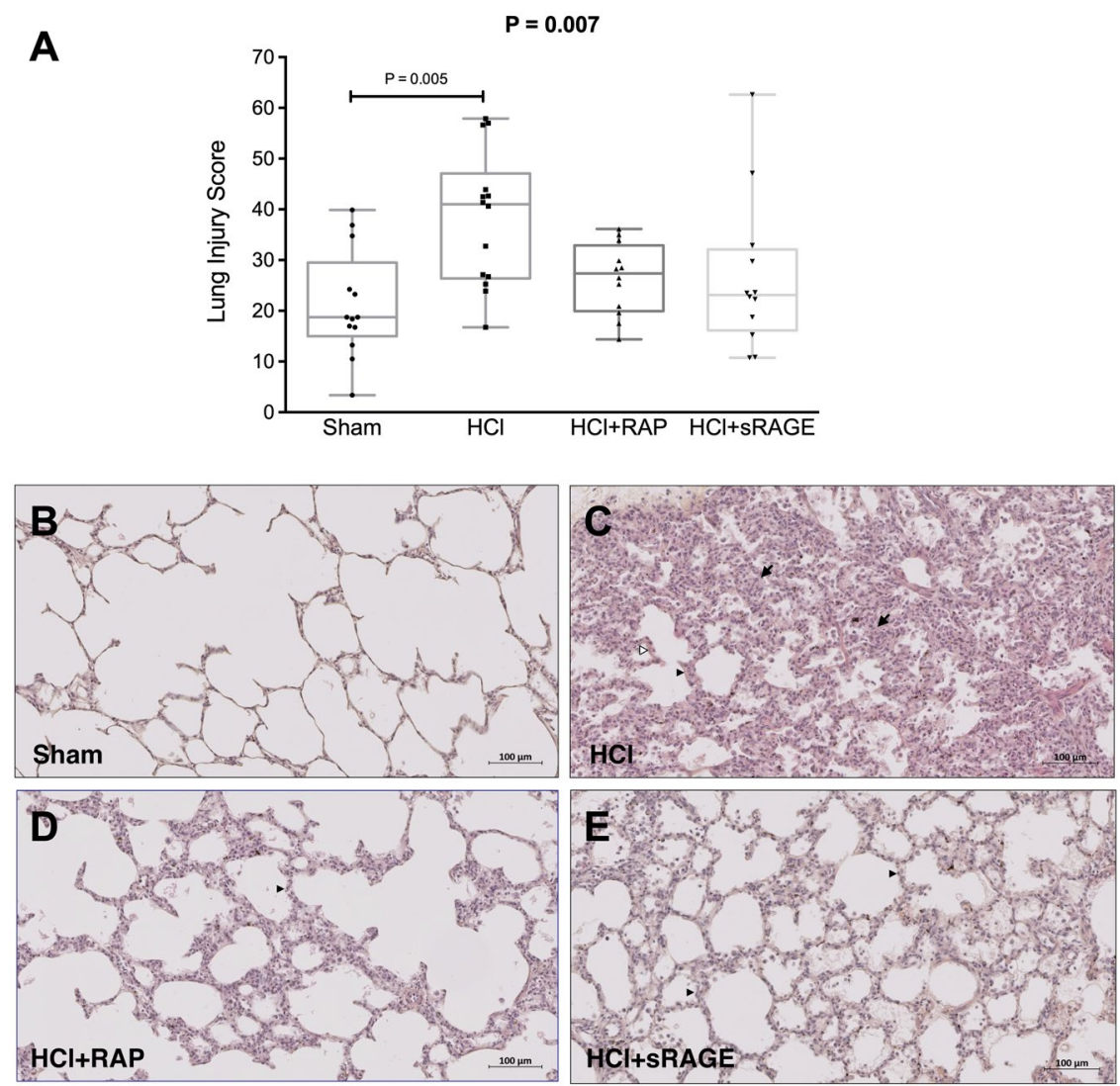

Figure 5. (A) RAGE inhibition decreases histological features of lung injury. Lung injury scores were higher in acid-injured $(\mathrm{HCl})$ than in uninjured piglets (Sham) and acid-injured piglets treated with RAGE antagonist peptide $(\mathrm{HCl}+\mathrm{RAP})$ or recombinant sRAGE $(\mathrm{HCl}+\mathrm{sRAGE})(\mathrm{n}=12$ per group). Values are reported as box and whisker plots. The Kruskal-Wallis test, with post-hoc Bonferroni test for pairwise comparisons were used. (B-E) Representative hematoxylin and eosin-stained sections at x20 original magnification of (B) uninjured piglets (Sham), (C) acid-injured piglets ( $\mathrm{HCl}$ ), acid-injured piglets treated with (D) RAGE antagonist peptide $(\mathrm{HCl}+\mathrm{RAP})$ or $(\mathrm{E})$ recombinant sRAGE $(\mathrm{HCl}+\mathrm{sRAGE})$. There was greater cellularity consisting mainly of neutrophils (black arrowheads), more alveolar wall thickening (white arrowheads), and more areas of atelectasis and increased alveolar disruption, proteinous debris, and hemorrhage (black arrows) in untreated, acid-injured than in uninjured or treated piglets. Scale bars, $100 \mu \mathrm{m}$.

improvement in oxygenation, and attenuation of histological lung injury, alveolar-capillary permeability and inflammation.

Growing preclinical evidence indicates that RAGE modulation might reduce lung injury, although some uncertainty persists ${ }^{23}$. To date, the use of sRAGE as a decoy receptor and the use of anti-RAGE antibody as a direct antagonist have shown beneficial effects on lung injury or sepsis. Indeed, RAGE ${ }^{-1-}$ mice had a survival advantage following cecal ligation puncture (CLP) when compared with wild-type mice ${ }^{17}$, and treatment with an anti-RAGE monoclonal antibody also decreased mortality in septic wild-type mice when compared to controls, even when treatment was administered $24 \mathrm{~h}$ after CLP. An anti-RAGE monoclonal antibody also improved survival in mice even when the treatment was given $6 \mathrm{~h}$ after intratracheal infection with Streptococcus pneumo$n i a e^{18}$. An intraperitoneal sRAGE treatment reduced neutrophil infiltration, lung permeability, proinflammatory cytokine production, NF- $\kappa$ B activation and the number of apoptotic cells in intratracheally LPS-challenged mice $^{19}$. However, another study showed that neither intratracheal nor intraperitoneal sRAGE treatment affected LPS-induced or Escherichia coli-induced acute pulmonary inflammation ${ }^{24}$. These conflicting findings on sRAGE may reflect the complexity of RAGE signalling occurring during lung injury ${ }^{25,26}$. Indeed, the RAGE pathway could be considered a double-edged sword, playing important roles both in tissue injury and in resolving the pathogenesis of an offending insult ${ }^{25}$.

The role of the balance between RAGE circulating isoforms and ligands in the regulation of RAGE signalling remains poorly investigated under physiological conditions and in specific diseases ${ }^{26-28}$. For example, the use of a model of ventilator-induced lung injury (VILI) using $\mathrm{RAGE}^{-1-}$ mice confirmed the contribution of RAGE activation to inflammatory cell influx into the alveolar compartment, but not to other VILI parameters, such as indices of alveolar barrier dysfunction or BAL IL-6, IL-1 $\beta$ and keratinocyte-derived chemokine ${ }^{29}$. By contrast, the use of a two-hit model of VILI and inhaled LPS demonstrated that RAGE ${ }^{-1-}$ mice had elevated cytokine and BAL chemokine levels and that RAGE deficiency did not affect the lung wet-to-dry ratio, total protein level or cell 
influx ${ }^{29}$. Moreover, administration of sRAGE to $\mathrm{RAGE}^{-/-}$mice attenuated the production of inflammatory mediators, probably because sRAGE can scavenge ligands that have the potential to activate other pattern-recognition receptors such as toll-like receptor $4^{30}$. To our knowledge, however, our study is the first to report beneficial effects of S100P-derived RAP administration in experimental ARDS, a finding that agrees with the results from a previous study of HMGB1-derived RAP in lung-injured mice ${ }^{31}$.

The current study confirms our own recent results that support the benefits of using sRAGE or an anti-RAGE antibody to restore AFC and attenuate major features of lung injury in a mouse model of acid-induced ARDS ${ }^{20}$. Our current findings might also suggest further hypotheses for mechanisms by which manipulating the RAGE pathway might counteract ARDS through AFC restoration. RAGE activation has been reported to stimulate $\mathrm{ENaC}$ activity and lung fluid clearance in uninjured mice via advanced glycation end-products ${ }^{32}$. Conversely, RAGE inhibition was associated with restored AFC and lung AQP-5 expression in acid-injured mice, when compared to controls ${ }^{20}$. However, the precise pathways linking RAGE modulation and active transepithelial fluid transport through the regulation of epithelial barrier integrity and channel expression or activity are not yet established.

Confirming the potential of RAGE modulation in a large animal model is a mandatory step prior to translation of ARDS treatment to the clinical setting. ARDS remains a syndrome that still lacks effective pharmacological therapies, but many issues require resolution before initiating the testing of RAGE inhibition strategies in human patients with ARDS. One issue is that RAGE inhibitors under development can take many forms, including derivatives of sRAGE that may act as decoy molecules, derivatives of RAGE ligands that block membrane RAGE, protein-protein interaction inhibitors, ligand release inhibitors and ligand inactivators ${ }^{33-36}$. Consequently, the choice of a specific agent (or of a combination of agents) deserves full comparative investigations. A second issue is that the intact function of the RAGE pathway may be crucial for antibacterial defence, as RAGE ${ }^{-1-}$ mice showed enhanced bacterial growth, increased bacterial dissemination and more severe inflammation in a model of bacterial peritonitis ${ }^{37}$. However, contradictory findings have been published and other studies have shown that RAGE inhibition, elicited either through genetic deletion or through the use of anti-RAGE or anti-HMGB1 antibodies, was associated with unchanged or decreased bacterial dissemination ${ }^{17,38,39}$. Indeed, although trials in patients with mild Alzheimer's disease did not support clinical efficacy of azeliragon (TTP448, vTv Therapeutics, High Point, NC, USA), an inhibitor of RAGE-amyloid $\beta$ protein interactions, no obvious safety issues were associated with its use ( $5 \mathrm{mg}$ orally once daily for 18 months) in human patients ${ }^{40-42}$. Future research should therefore investigate the extent to which our current findings might translate to the treatment of critically ill patients with ARDS in terms of the timing, dosing and methods of administration of RAGE inhibition candidates, with a focus on their efficacy and safety profiles.

Our study has some limitations. One limitation is that we mainly focused on the major criteria of experimental ARDS, including AFC measurements ${ }^{43}$; however, neither sRAGE nor membrane RAGE were measured and the assessment of animals was limited to four hours after injury. Therefore, the extrapulmonary and longer-term effects of RAGE inhibition in this model remain unknown. In addition, our experiments should be independently replicated to strengthen the value of our findings. A second limitation is that we suggested restored AFC and lung expression of epithelial channels as potential mechanisms for the beneficial effects of RAGE inhibition, but we acknowledge these are only exploratory, hypothesis-generating findings as we did not measure their protein expression in the lung and were unable to precisely characterise the specific pathways by which RAP and sRAGE might alleviate lung injury in ARDS, thus prompting further investigation. Third, we were unable to test additional means of inhibiting RAGE, such as with FPS-ZM1 (a high-affinity specific blocker that inhibits ligand binding to RAGE that was not used in this study for financial reasons $)^{44}$, or multiple routes of administration, doses and timings for treatment with RAP and sRAGE, and whether a RAGE inhibition strategy may reduce lung injury and improve AFC when applied after experimental ARDS is established remains unknown. Furthermore, our findings may hold true only for acid-induced ARDS, so additional validation is warranted in other settings, such as pulmonary and extrapulmonary sepsis (the most frequent cause of ARDS), prior to considering clinical translation into more complex critical care scenarios that frequently combine multiple organ failure.

In conclusion, a RAGE inhibition strategy, using either recombinant sRAGE or RAP, was associated with restored AFC and attenuated lung injury in a translational piglet model of acid-induced ARDS. These results, which reinforce those from previously published preclinical studies in smaller animals, might represent an important step towards future clinical translation of this treatment strategy, although further investigations are needed to confirm the safety of modulating RAGE in patients with ARDS.

\section{Materials and Methods}

Animal model. Animals were maintained and all procedures were performed with the approval of the ethics committee of the French Ministère de l'Education Nationale, de l'Enseignement Supérieur et de la Recherche in the Centre International de Chirurgie Endoscopique, School of Medicine - University of Clermont-Ferrand (approval number 01505.03). All experiments were performed in accordance with the "Animal Research: Reporting In Vivo Experiments" (ARRIVE) guidelines (Supplementary Checklist) ${ }^{45}$.

Two-month-old white Landrace male piglets with mean ( \pm standard deviation $(S D))$ weights of $10.1( \pm 1.1)$ $\mathrm{kg}$ were restricted from food overnight but allowed free access to water, before receiving premedication with intramuscular azaperone $\left(2 \mathrm{mg} \cdot \mathrm{kg}^{-1}\right)$. General anaesthesia was then induced with intravenous propofol ( $3 \mathrm{mg}$. $\left.\mathrm{kg}^{-1}\right)$ and sufentanil $\left(0.3 \mu \mathrm{g} \cdot \mathrm{kg}^{-1}\right)$ prior to orotracheal intubation (6-mm ID cuffed endotracheal tube), and anaesthesia was maintained with continuous intravenous infusion of propofol $\left(5 \mathrm{mg} \cdot \mathrm{kg}^{-1} \cdot \mathrm{h}^{-1}\right)$ and remifentanil $\left(10-20 \mu \mathrm{g} \cdot \mathrm{kg}^{-1} \cdot \mathrm{h}^{-1}\right)$. The body temperature of the pigs was kept at approximately $38^{\circ} \mathrm{C}$ using warm blankets (Medi-therm II, Gaymar Industries, Orchard Park, NY, USA). Mechanical ventilation was delivered, with the pigs

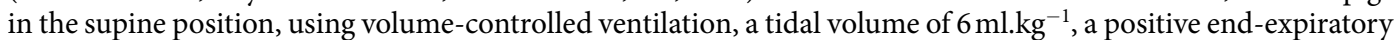
pressure (PEEP) of $5 \mathrm{cmH}_{2} \mathrm{O}$ and an $\mathrm{FiO}_{2}$ of $40 \%$ (Engström Carestation, GE Healthcare, Chicago, IL, USA). The 
respiratory rate was adjusted to maintain the end-tidal carbon dioxide between 35 and $45 \mathrm{mmHg}$. Central venous access through the jugular vein and catheterisation of the femoral artery allowed retrieval of serial blood samples and continuous hemodynamic monitoring (arterial pressure, cardiac index and EVLW, as indexed to body weight ${ }^{46}$ ) with a PiCCO + device (Maquet, Rastatt, Germany). The electrocardiogram activity and the peripheral oxygen saturation $\left(\mathrm{SpO}_{2}\right)$ arterial pressure were also monitored continuously (IntelliVue MP40, Phillips, Amsterdam, The Netherlands).

A total of 48 piglets was randomly allocated to four groups by means of computer software (Microsoft Office Excel 2003, Microsoft Corporation, Redmond, WA, USA). The "Sham" group was composed of control animals without lung injury $(\mathrm{n}=12)$. The "HCl group" consisted of animals with HCl-induced lung injury $(\mathrm{n}=12)$. Animals with $\mathrm{HCl}$-induced lung injury and receiving intravenous treatment with RAP (EMD Millipore, Burlington, MA, USA) $\left(3 \mu \mathrm{g} \cdot \mathrm{kg}^{-1}\right)$ defined the "RAP group" $(\mathrm{n}=12)$. The "sRAGE group" $(\mathrm{n}=12)$ included animals with $\mathrm{HCl}$-induced lung injury that also received intravenous treatment with sRAGE (3 mg. $\mathrm{kg}^{-1}$ ) (Recombinant Human RAGE Fc Chimera, R\&D Systems, Minneapolis, MN). Intravenous RAP or sRAGE was administered 30 minutes prior to the $\mathrm{HCl}$ instillation, the dose and timing were based on limited data from previous studies ${ }^{17,20,21}$

Acid aspiration-induced ARDS was produced by intratracheal instillation of $0.05 \mathrm{M} \mathrm{HCl}, \mathrm{pH} 1.41\left(4 \mathrm{ml}^{\mathrm{kg}} \mathrm{kg}^{-1}\right.$ body weight), over $3 \mathrm{~min}$ at the level of the carina ${ }^{22}$. Based on previous studies, lung injury was considered established when the $\mathrm{PaO}_{2} / \mathrm{FiO}_{2}$ ratio decreased to $25 \%$ from the baseline, approximately one hour after airway $\mathrm{HCl}$ instillation ${ }^{22,47}$.

Animals were maintained under anaesthesia and mechanical ventilation for four hours after $\mathrm{HCl}$ instillation. At the end of ventilation, and after arterial blood sampling and BAL with $50 \mathrm{~mL}$ of saline, the piglets were sacrificed with intravenous pentobarbital ( $\left.150 \mathrm{mg} \cdot \mathrm{kg}^{-1}\right)$.

Outcome measures. Primary outcome. The primary outcome was the net AFC rate. Undiluted pulmonary oedema fluid samples were collected from the animals at baseline and four hours later, as previously described $^{12,48-53}$. Briefly, a soft 14-Fr-gauge suction catheter (ConvaTec, Lejre, Denmark) was advanced into a wedged position in a distal bronchus via the endotracheal tube and oedema fluid was collected in a suction trap by applying gentle suction. All samples were centrifuged at $240 \times \mathrm{g}$ at $4{ }^{\circ} \mathrm{C}$ for $10 \mathrm{~min}$ in a refrigerated centrifuge. The supernatants were collected and the total protein concentration was determined in duplicate with a colorimetric method (Pierce BCA Protein Assay Kit, ThermoFisher Scientific, Waltham, MA, USA). Because the rate of clearance of oedema fluid from the alveolar space is much faster than the rate of protein removal ${ }^{54}$, the net AFC rate was calculated as Percent $\mathrm{AFC}=100 \times[1$ - (initial oedema protein/final oedema total protein) $]$ and thereafter was reported as $\% / \mathrm{h}$. All samples had a coefficient of variation of less than $10 \%$.

Secondary outcomes. Secondary outcomes were major criteria for experimental ARDS, as recommended by the American Thoracic Society ${ }^{43}$.

At baseline and every hour for four hours, arterial blood gases were measured to assess $\mathrm{PaO}_{2} / \mathrm{FiO}_{2}, \mathrm{PaCO}_{2}, \mathrm{pH}$ and serum lactate (Epoc ${ }^{\circledR}$ Blood Analysis System, Siemens Healthineers, Erlangen, Germany), and respiratory (tidal volume, inspiratory plateau pressure, compliance of the respiratory system, driving pressure) and hemodynamic (mean arterial pressure, cardiac index, EVLW) parameters were collected.

In addition to measuring the ELVW through transpulmonary thermodilution, the alteration of the alveolar-capillary barrier was assessed by measuring the BAL level of total protein at four hours as a surrogate for alveolar oedema.

Alveolar inflammation was assessed by duplicate determination of the levels of proinflammatory cytokines, including TNF- $\alpha$, IL-6, IL-1 $\beta$ and IL-18, in the BAL at four hours. These determinations were made using the Bio-Plex 200 System, which is based on Luminex xMAP Technology (Bio-Rad, Hercules, CA, USA) and a Milliplex MAP Kit (Luminex xMAP technology, EMD Millipore, Burlington, MA, USA). All samples had a coefficient of variation of less than $10 \%$.

After sacrificing the piglets, whole lungs were removed, fixed with alcoholic acetified formalin and embedded in paraffin. Slices at $10-\mu \mathrm{m}$ thickness were stained with hematoxylin and eosin (Sigma-Aldrich, Saint-Louis, MO, USA). Histological evidence of lung injury was assessed using a standardised, validated histology injury score derived from the following calculation: score $=[20 \times(\mathrm{i})+14 \times(\mathrm{ii})+7 \times(\mathrm{iii})+7 \times(\mathrm{iv})+2 \times(\mathrm{v})] /($ number of fields $\times 100)(\text { Supplementary Table } 1)^{43}$.

The researchers performing animal experiments and collecting samples were not blinded to group allocation. However, the researchers who performed measurements from the biological samples (e.g., blood gas analyses, protein and cytokine measurement, histology score) and the statistician who performed analyses were blinded.

Statistical analysis. All analyses were performed using Prism 6 (GraphPad Software, La Jolla, CA, USA) or Stata version 14 (StataCorp, College Station, TX, USA).

Categorical data were expressed as numbers and percentages, and quantitative data as mean and SD or median and interquartile range [IQR] according to their statistical distribution. Baseline characteristics between groups were compared using Student's t-test or Mann-Whitney test were considered for quantitative parameters according to the t-test assumption (normality assumption using Shapiro-Wilk test and homoscedasticity with FisherSnedecor test). Categorical data were compared among groups using the Chi-square test or Fisher's exact test.

Analysis of physiological parameters with repeated measurements was carried out by two-way repeated measures analyses of variance ANOVA when appropriate; Kruskal-Wallis test with Bonferroni tests were used for pairwise comparisons. Time $\times$ group interactions and post-hoc comparisons were verified using random effects models to analyse longitudinal evolution of variables: (i) considering between- and within-subject 
variability (random subject effects: random intercept and slope) and (ii) evaluating fixed effects: group, time and time $\times$ group interaction. The residual normality was checked for all models. Values were log-transformed for all variables to achieve normality prior to performing random effects models.

According to the principles of the 3Rs (Replacement, Reduction and Refinement), the smallest number of animals was used (12 animals in each group) that could detect a mean difference of $5 \% / \mathrm{h}(\mathrm{SD}=4)$ in the net AFC rate at four hours after lung injury (primary outcome) between $\mathrm{HCl}$-injured animals and $\mathrm{HCl}$-injured animals receiving sRAGE or RAP, while still considering the alpha and beta risks of $5 \%$ (bilateral) and 10\%, respectively. A statistical power of $90 \%$ was considered sufficient to allow multiple comparisons between groups.

\section{References}

1. Bellani, G. et al. Epidemiology, Patterns of Care, and Mortality for Patients With Acute Respiratory Distress Syndrome in Intensive Care Units in 50 Countries. JAMA 315, 788-800 (2016).

2. Thompson, B. T., Chambers, R. C. \& Liu, K. D. Acute Respiratory Distress Syndrome. N. Engl. J. Med. 377, 562-572 (2017).

3. Fan, E. et al. An Official American Thoracic Society/European Society of Intensive Care Medicine/Society of Critical Care Medicine Clinical Practice Guideline: Mechanical Ventilation in Adult Patients with Acute Respiratory Distress Syndrome. Am. J. Respir. Crit. Care Med. 195, 1253-1263 (2017).

4. ARDS Definition Task Force et al. Acute respiratory distress syndrome: the Berlin Definition. JAMA 307, 2526-2533 (2012).

5. Ware, L. B. \& Matthay, M. A. Alveolar fluid clearance is impaired in the majority of patients with acute lung injury and the acute respiratory distress syndrome. Am. J. Respir. Crit. Care Med. 163, 1376-1383 (2001).

6. McAuley, D. F., Frank, J. A., Fang, X. \& Matthay, M. A. Clinically relevant concentrations of beta2-adrenergic agonists stimulate maximal cyclic adenosine monophosphate-dependent airspace fluid clearance and decrease pulmonary edema in experimental acid-induced lung injury. Crit. Care Med. 32, 1470-1476 (2004).

7. Matthay, M. A. Resolution of pulmonary edema. Thirty years of progress. Am. J. Respir. Crit. Care Med. 189, 1301-1308 (2014).

8. Shirasawa, M. et al. Receptor for advanced glycation end-products is a marker of type I lung alveolar cells. Genes Cells $\mathbf{9 , 1 6 5 - 1 7 4}$ (2004).

9. Schmidt, A. M., Yan, S. D., Yan, S. F. \& Stern, D. M. The biology of the receptor for advanced glycation end products and its ligands. Biochim. Biophys. Acta 1498, 99-111 (2000).

10. Uchida, T. et al. Receptor for advanced glycation end-products is a marker of type I cell injury in acute lung injury. Am. J. Respir. Crit. Care Med. 173, 1008-1015 (2006).

11. Calfee, C. S. et al. Plasma receptor for advanced glycation end products and clinical outcomes in acute lung injury. Thorax 63 , 1083-1089 (2008).

12. Jabaudon, M. et al. Soluble Receptor for Advanced Glycation End-Products Predicts Impaired Alveolar Fluid Clearance in Acute Respiratory Distress Syndrome. Am. J. Respir. Crit. Care Med. 192, 191-199 (2015).

13. Jabaudon, M. et al. Soluble form of the receptor for advanced glycation end products is a marker of acute lung injury but not of severe sepsis in critically ill patients. Crit. Care Med. 39, 480-488 (2011).

14. Briot, R. et al. Elevated levels of the receptor for advanced glycation end products, a marker of alveolar epithelial type I cell injury, predict impaired alveolar fluid clearance in isolated perfused human lungs. Chest 135, 269-275 (2009).

15. Mrozek, S. et al. Elevated Plasma Levels of sRAGE Are Associated With Nonfocal CT-Based Lung Imaging in Patients With ARDS: A Prospective Multicenter Study. Chest 150, 998-1007 (2016).

16. Jabaudon, M. et al. Plasma sRAGE is independently associated with increased mortality in ARDS: a meta-analysis of individual patient data. Intensive Care Med. 44, 1388-1399 (2018).

17. Lutterloh, E. C. et al. Inhibition of the RAGE products increases survival in experimental models of severe sepsis and systemic infection. Crit. Care 11, R122 (2007)

18. Christaki, E. et al. A monoclonal antibody against RAGE alters gene expression and is protective in experimental models of sepsis and pneumococcal pneumonia. Shock 35, 492-498 (2011).

19. Zhang, H. et al. Role of soluble receptor for advanced glycation end products on endotoxin-induced lung injury. Am. J. Respir. Crit. Care Med. 178, 356-362 (2008).

20. Blondonnet, R. et al. RAGE inhibition reduces acute lung injury in mice. Sci. Rep. 7, 7208 (2017).

21. Arumugam, T., Ramachandran, V., Gomez, S. B., Schmidt, A. M. \& Logsdon, C. D. S100P-derived RAGE antagonistic peptide reduces tumor growth and metastasis. Clin. Cancer Res. 18, 4356-4364 (2012).

22. Ambrosio, A. M. et al. Effects of positive end-expiratory pressure titration and recruitment maneuver on lung inflammation and hyperinflation in experimental acid aspiration-induced lung injury. Anesthesiology 117, 1322-1334 (2012).

23. Creagh-Brown, B. C., Quinlan, G. J., Evans, T. W. \& Burke-Gaffney, A. The RAGE axis in systemic inflammation, acute lung injury and myocardial dysfunction: an important therapeutic target? Intensive Care Med. 36, 1644-1656 (2010).

24. Ramsgaard, L. et al. Lack of the Receptor for Advanced Glycation End-Products Attenuates $<$ italic $>$ E. coli $</$ italic $>$ Pneumonia in Mice. PLoS One 6, e20132 (2011).

25. Bierhaus, A. et al. Understanding RAGE, the receptor for advanced glycation end products. J. Mol. Med. 83, 876-886 (2005).

26. Schmidt, A. M., Yan, S. D., Yan, S. F. \& Stern, D. M. The biology of the receptor for advanced glycation end products and its ligands. Biochim. Biophys. Acta 1498, 99-111 (2000)

27. Xie, J., Méndez, J. D., Méndez-Valenzuela, V. \& Aguilar-Hernández, M. M. Cellular signalling of the receptor for advanced glycation end products (RAGE). Cell. Signal. 25, 2185-2197 (2013).

28. Jabaudon, M. et al. Soluble Forms and Ligands of the Receptor for Advanced Glycation End-Products in Patients with Acute Respiratory Distress Syndrome: An Observational Prospective Study. PLoS One 10, e0135857 (2015).

29. Kuipers, M. T. et al. The receptor for advanced glycation end products in ventilator-induced lung injury. Intensive Care Med Exp 2, $22(2014)$.

30. Andersson, U. \& Tracey, K. J. HMGB1 is a therapeutic target for sterile inflammation and infection. Annu. Rev. Immunol. 29, 139-162 (2011).

31. Lee, S. et al. Production and application of HMGB1 derived recombinant RAGE-antagonist peptide for anti-inflammatory therapy in acute lung injury. Eur. J. Pharm. Sci. 114, 275-284 (2017).

32. Downs, C. A., Kreiner, L. H., Johnson, N. M., Brown, L. A. \& Helms, M. N. Receptor for Advanced Glycation End-Products Regulates Lung Fluid Balance via Protein Kinase C-gp91(phox) Signaling to Epithelial Sodium Channels. Am. J. Respir. Cell Mol. Biol. 52, 75-87 (2015).

33. Bakris, G. L. et al. Advanced glycation end-product cross-link breakers. A novel approach to cardiovascular pathologies related to the aging process. Am. J. Hypertens. 17, 23S-30S (2004).

34. Yamagishi, S.-I. Potential clinical utility of advanced glycation end product cross-link breakers in age- and diabetes-associated disorders. Rejuvenation Res. 15, 564-572 (2012).

35. Aldini, G. et al. Molecular strategies to prevent, inhibit, and degrade advanced glycoxidation and advanced lipoxidation end products. Free Radic. Res. 47(Suppl 1), 93-137 (2013). 
36. Manigrasso, M. B. et al. Small Molecule Inhibition of Ligand-Stimulated RAGE-DIAPH1 Signal Transduction. Sci. Rep. 6, 22450 (2016).

37. van Zoelen, M. A. D. et al. Receptor for advanced glycation end products facilitates host defense during Escherichia coli-induced abdominal sepsis in mice. J. Infect. Dis. 200, 765-773 (2009).

38. Yang, H. et al. Reversing established sepsis with antagonists of endogenous high-mobility group box 1. Proc. Natl. Acad. Sci. USA 101, 296-301 (2004).

39. van Zoelen, M. A. D. et al. The receptor for advanced glycation end products impairs host defense in pneumococcal pneumonia. J. Immunol. 182, 4349-4356 (2009).

40. Galasko, D. et al. Clinical trial of an inhibitor of RAGE-A $\beta$ interactions in Alzheimer disease. Neurology 82, 1536-1542 (2014).

41. Burstein, A. H. et al. Effect of TTP488 in patients with mild to moderate Alzheimer's disease. BMC Neurol. 14, 12 (2014).

42. Burstein, A. H. et al. Development of Azeliragon, an Oral Small Molecule Antagonist of the Receptor for Advanced Glycation Endproducts, for the Potential Slowing of Loss of Cognition in Mild Alzheimer's Disease. J Prev Alzheimers Dis 5, 149-154 (2018).

43. Matute-Bello, G. et al. An official American Thoracic Society workshop report: features and measurements of experimental acute lung injury in animals. Am. J. Respir. Cell Mol. Biol. 44, 725-738 (2011).

44. Lee, H., Lee, J., Hong, S.-H., Rahman, I. \& Yang, S.-R. Inhibition of RAGE Attenuates Cigarette Smoke-Induced Lung Epithelial Cell Damage via RAGE-Mediated Nrf2/DAMP Signaling. Front. Pharmacol. 9, 684 (2018).

45. Kilkenny, C., Browne, W. J., Cuthill, I. C., Emerson, M. \& Altman, D. G. Improving bioscience research reporting: the ARRIVE guidelines for reporting animal research. PLoS Biol. 8, e1000412 (2010).

46. Jozwiak, M., Teboul, J.-L. \& Monnet, X. Extravascular lung water in critical care: recent advances and clinical applications. Ann. Intensive Care 5, 38 (2015).

47. Marumo, C. K. et al. Hemodynamic effects of PEEP in a porcine model of HCl-induced mild acute lung injury. Acta Anaesthesiol. Scand. 53, 190-202 (2009).

48. Verghese, G. M., Ware, L. B., Matthay, B. A. \& Matthay, M. A. Alveolar epithelial fluid transport and the resolution of clinically severe hydrostatic pulmonary edema. J. Appl. Physiol. 87, 1301-1312 (1999).

49. Sakuma, T. et al. Alveolar fluid clearance in the resected human lung. Am. J. Respir. Crit. Care Med. 150, 305-310 (1994).

50. Matthay, M. A. \& Wiener-Kronish, J. P. Intact epithelial barrier function is critical for the resolution of alveolar edema in humans. Am. Rev. Respir. Dis. 142, 1250-1257 (1990).

51. Ware, L. B. \& Matthay, M. A. Alveolar fluid clearance is impaired in the majority of patients with acute lung injury and the acute respiratory distress syndrome. Am. J. Respir. Crit. Care Med. 163, 1376-1383 (2001).

52. Ware, L. B., Golden, J. A., Finkbeiner, W. E. \& Matthay, M. A. Alveolar epithelial fluid transport capacity in reperfusion lung injury after lung transplantation. Am. J. Respir. Crit. Care Med. 159, 980-988 (1999).

53. Constantin, J.-M. et al. Response to recruitment maneuver influences net alveolar fluid clearance in acute respiratory distress syndrome. Anesthesiology 106, 944-951 (2007).

54. Berthiaume, Y., Staub, N. C. \& Matthay, M. A. Beta-adrenergic agonists increase lung liquid clearance in anesthetized sheep. J. Clin. Invest. 79, 335-343 (1987).

\section{Acknowledgements}

This work was supported by grants from the Auvergne Regional Council ("Programme Nouveau Chercheur de la Région Auvergne” 2013) and the French Agence Nationale de la Recherche and the Direction Générale de l'Offre de Soins ("Programme de Recherche Translationnelle en Santé" ANR-13-PRTS-0010). The funders had no influence in the study design, conduct, and analysis or in the preparation of this article.

\section{Author Contributions}

Jules Audard, Vincent Sapin, Jean-Michel Constantin, and Matthieu Jabaudon conceived and designed the study. Jules Audard, Thomas Godet, Raiko Blondonnet, Jean-Baptiste Joffredo, and Matthieu Jabaudon performed the experiments. Jules Audard, Raiko Blondonnet, Bertille Paquette, Corinne Belville, Marilyne Lavergne, Christelle Gross, and Matthieu Jabaudon collected and analysed the data. Jules Audard, Thomas Godet, Justine Pasteur, Damien Bouvier, Loic Blanchon, Bruno Pereira, and Matthieu Jabaudon interpreted the data. Vincent Sapin, Jean-Michel Constantin and Matthieu Jabaudon acquired the funding and supervised the study. Jules Audard and Matthieu Jabaudon wrote the paper, all other authors reviewed and edited the manuscript prior to submission.

\section{Additional Information}

Supplementary information accompanies this paper at https://doi.org/10.1038/s41598-019-45798-5.

Competing Interests: The authors declare no competing interests.

Publisher's note: Springer Nature remains neutral with regard to jurisdictional claims in published maps and institutional affiliations.

Open Access This article is licensed under a Creative Commons Attribution 4.0 International License, which permits use, sharing, adaptation, distribution and reproduction in any medium or format, as long as you give appropriate credit to the original author(s) and the source, provide a link to the Creative Commons license, and indicate if changes were made. The images or other third party material in this article are included in the article's Creative Commons license, unless indicated otherwise in a credit line to the material. If material is not included in the article's Creative Commons license and your intended use is not permitted by statutory regulation or exceeds the permitted use, you will need to obtain permission directly from the copyright holder. To view a copy of this license, visit http://creativecommons.org/licenses/by/4.0/.

(C) The Author(s) 2019 